\title{
DDITORIAT
}

\section{CONSTRUYENDO FUTURO}

El pasado mes de Mayo, la Sociedad Cientifica de Enfermeria SCELE celebro su congreso bianual en la Universitat Jaume I de Castellón.

Se trataba de la VI edición es decir 12 años de vida de la Sociedad y la primera vez que se celebraba en una Universidad diferente a la de Alicante.

La Sociedad tiene una forma de hacer que se manifiesta en los congresos, actividades y publicaciones. Se trata de una forma actual, adaptada a la generación actual de Enfermeria: Mucha comunicación directa y on-line; poca pérdidad de tiempo; pocos fastos y coste-calidad ajustados.

Presentamos un resumen del VI congreso:

Duración: 2 dias,

URL. http://www.scele.org/web scele/jornadas scele.htm

Contenido científico: 3 talleres pre-congresuales; 3 mesas redondas;13 posters; 16 comunicaciones orales y 100 congresistas.

Espacio y apoyo: Universitat Jaume I (entidad pública)

Proyección científica: A través de la revista RECIEN de acceso libre a texto completo.

Con este ejemplo de actividad y modelo de Sociedad científica se pretende visualizar la necesidad de reciclar todos los procesos productivos educativos y sanitarios para adaptarlos al siglo XXI una vez que estamos 
totalmente inmersos en la era de la comunicación, sociedad de la información y etapa científica de la Enfermería.

Los/as actuales Enfermeros/as estudian con la perspectiva de los 3 niveles académicos y reciben información a la velocidad que cambia el mundo.

Conociendo los medios con los que se comunican en un muy corto plazo, entenderán la Enfermería igual que la vida, de otra manera. Si la Enfermería actual no se apoya para el trabajo, la educación y la investigación con la experiencia de la generación profesional, el punto de vista de la generación digital ; una comunicación on-line y aprendizaje en la diversidad, unido a formas de trabajo competitivas y orientadas hacia las personas en sus vertientes bio-psico-sociales, la Enfermería española puede estar en riesgo de perder el tren del siglo XXI.

Es el momento menos adecuado para dejarse envolver por otras perspectivas que emanan de profesiones que han incorporado la investigación a sus métodos antes que la Enfermería y además compiten por puestos de trabajo muy relacionados.

Se necesita mas que nunca una Enfermería fuerte y sólida que camine unida trabajando para observar en un corto plazo una renovación intensa que se apoye en la experiencia y crezca con ideas de futuro.

SCELE es un ejemplo de este enfoque y anima a los profesionales de Enfermería a participar en cualquiera de sus vertientes como Sociedad y enviar trabajos científicos para que una vez evaluados, sean difundido y puedan servir de ayuda u orientación a otros/as enfermeros/as.

Comité editorial RECIEN

Noviembre, 2012 